\title{
Spinal Arteriovenous Vascular Malformations in Patients with Neural Tube Defects
}

\author{
(D)E. Giordan, DC. Bortolotti, (D) G. Lanzino, and (DW. Brinjikji
}

\begin{abstract}
BACKGROUND AND PURPOSE: Neural tube defects, such as tethered cord, intradural lipoma, or myelomeningocele may coexist with spinal vascular malformations. The coexistence of these 2 rare entities is suggestive of a causal relationship between them, which may lead to further understanding of their pathogenesis. We present a series of 6 patients with epidural spinal arteriovenous fistulas associated with neural tube defects.
\end{abstract}

MATERIALS AND METHODS: We retrieved cases of spinal vascular malformations associated with neural tube defects seen at our institution. The clinical presentation, MR imaging/MRA and angiographic imaging, treatment outcomes, and long-term neurologic outcomes were analyzed. Descriptive statistical analyses are reported.

RESULTS: Six patients with epidural arteriovenous fistulas and neural tube defects were included in this study. The mean age at presentation was 42 years, and the most common presenting symptoms were lower extremity weakness followed by sensory disturbances and bladder/bowel dysfunction. In most cases (5/6), the fistulas were located at the sacral level. All cases were fed by the lateral sacral artery (6/6). Four patients had prior spine surgery, but the fistula was in the operative bed in 2 cases. All fistulas were extradural with secondary intradural venous drainage. Five patients underwent transarterial embolization with Onyx, and 1 patient had a treatment-related complication.

CONCLUSIONS: It is conceivable that there is a pathophysiologic link between neural tube defects and development of spinal vascular malformations. Delayed neurologic deterioration or high conus signal in a patient with a neural tube defect should suggest the possibility of such an association.

$\mathbf{N}$ eural tube defects are relatively uncommon abnormalities of spinal cord and spinal column formation. They occur consequent to failure or improper fusion of the neural tube during embryologic development. Spinal epidural arteriovenous fistulas or malformations are rare entities, which have been sporadically associated with neural tube defects, though a formal association between the 2 conditions has not yet been established. The coexistence of 2 uncommon conditions (ie, neural tube defect and spinal vascular malformation) in the same patient may suggest a causal relationship rather than mere coincidence. We present the first series of spinal epidural arteriovenous fistulas associated with neural tube defects along with an extensive review of the litera-

Received June 6, 2017; accepted after revision October 30.

From the Departments of Neurologic Surgery (E.G., G.L.) and Radiology (G.L., W.B.) Mayo Clinic, Rochester, Minnesota; and Department of Neurosurgery (C.B.), Istituto di Ricovero e Cura a Carattere Scientifico Istituto delle Scienze Neurologiche di Bologna, Bologna, Italy.

Please address correspondence to Giuseppe Lanzino, MD, Mayo Clinic, 200 1st St SW, Rochester, MN 55905; e-mail: lanzino.giuseppe@mayo.edu; @wbrinjikji

$\equiv$ Indicates article with supplemental on-line table.

http://dx.doi.org/10.3174/ajnr.A5498 ture. On the basis of this association, we suggest that these 2 rare entities could share a common pathophysiologic origin.

\section{MATERIALS AND METHODS \\ Patient Selection}

We retrospectively reviewed all cases of spinal vascular malformations associated with neural tube defects evaluated at the Mayo Clinic. Selection criteria included patients with lipomeningocele, myelomeningocele, dermoid cyst, neuroenteric cyst, tethered cord, intradural lipoma, and diastematomyelia with a coexisting epidural, dural, or intradural arteriovenous fistula or malformation. Patients who underwent a prior spinal surgery for spina bifida repair were included in the study.

\section{Image Analysis}

MR imaging and angiographic findings were reviewed by a neuroradiologist. All patients underwent spinal MR imaging and conventional spinal angiography. The presence of flow voids, increased T2 hyperintensity, or spinal cord enhancement was documented. Selective spinal angiography was performed in all cases to identify the fistulous point, feeder location and number, and venous 
Summary of cases of spinal epidural arteriovenous fistula and neural tube defects

\begin{tabular}{|c|c|c|c|c|c|c|c|c|c|c|}
\hline \multirow[b]{2}{*}{$\begin{array}{l}\text { Case } \\
\text { No. }\end{array}$} & \multirow{2}{*}{$\begin{array}{l}\text { Age } \\
\text { (yr), } \\
\text { Sex }\end{array}$} & \multirow[b]{2}{*}{$\begin{array}{l}\text { Fistula } \\
\text { Location }\end{array}$} & \multicolumn{4}{|c|}{ Presentation } & \multirow{2}{*}{$\begin{array}{l}\text { Length of } \\
\text { Clinical } \\
\text { FU (mo) }\end{array}$} & \multirow[b]{2}{*}{$\begin{array}{l}\text { Long-Term } \\
\text { Outcome }\end{array}$} & \multirow{2}{*}{$\begin{array}{c}\text { Prior } \\
\text { Surgery (Type } \\
\text { of Surgery) }\end{array}$} & \multirow[b]{2}{*}{$\begin{array}{c}\text { Associatec } \\
\text { NTD }\end{array}$} \\
\hline & & & $\begin{array}{c}\text { Sensory } \\
\text { Symptoms }\end{array}$ & $\begin{array}{c}\text { Bladder } \\
\text { Dysfunction }\end{array}$ & $\begin{array}{l}\text { Bowel/Sexual } \\
\text { Dysfunction }\end{array}$ & $\begin{array}{c}\text { Motor } \\
\text { Symptoms }\end{array}$ & & & & \\
\hline 1 & $46, M$ & $\mathrm{~S}$ & $\mathrm{Y}$ & $\mathrm{Y}$ & $\mathrm{N}$ & $\mathrm{N}$ & 2 & Unchanged & $\mathrm{N}$ & $\mathrm{TC}+\mathrm{IL}$ \\
\hline 2 & $44, \mathrm{~F}$ & L4 & $Y$ & $\mathrm{~N}$ & $\mathrm{~N}$ & $Y$ & 3 & Worsened & Y (MMC repair) & MMC \\
\hline 3 & $65, \mathrm{~F}$ & $S$ & $Y$ & $\mathrm{Y}$ & $Y$ & Y & 4 & Improved & Y (laminectomy) & $\mathrm{TC}+\mathrm{DS}$ \\
\hline 4 & $64, M$ & S & $Y$ & $Y$ & $\mathrm{Y}$ & Y & 3 & Improved & $\mathrm{N}$ & $\mathrm{TC}+\mathrm{IL}$ \\
\hline 5 & $57, \mathrm{~F}$ & S & $Y$ & $Y$ & $Y$ & Y & NA & NA & Y (MMC repair) & MMC \\
\hline 6 & $64, \mathrm{~F}$ & S & $Y$ & $\mathrm{~N}$ & $\mathrm{~N}$ & Y & 6 & Improved & Y (laminectomy) & $\mathrm{TC}$ \\
\hline
\end{tabular}

Note:-N indicates no; Y, yes; NA, not applicable/not defined; NTD, neural tube defect; TC, tethered cord; IL, intrathecal lipoma; MMC, myelomeningocele; DS, diastematomyelia; FU, follow-up; S, sacrum.

draining pattern. Postoperative MRA or DSA was performed in all patients undergoing treatment, to assess AVF obliteration. Postoperative imaging follow-up ranged from 2 to 14 months.

\section{Data Collection}

The study sample was collected by reviewing the surgical and radiologic data base. Patient history, clinical examination, radiologic findings, and follow-up information were obtained from digital records. Both the modified Rankin Scale and the Aminoff Motor Disability Scale scores were determined retrospectively. The timing and presence of any spine operation were documented. Fistulas were considered possibly related to a prior operation if the fistula was in the operative bed. In cases of patients who had an operation and development of a fistula at a distant location (ie, lower sacral fistula following lumbar laminectomies and so forth), the fistula was not thought to be related to the prior surgery. Lesions were considered "missed" on imaging if there was clear MR imaging evidence of a fistula and the patient was treated for a different disease entity (ie, transverse myelitis, degenerative disease, neuropathy, and so forth). MR imaging evidence of a fistula included high T2 cord signal in the presence of flow voids with or without cord enhancement.

\section{Statistical Analysis}

No formal statistical comparisons were performed. Descriptive results are presented as mean \pm SD for continuous variables and number (percentage) for categoric variables. All data analyses were performed using the statistical software package JMP 13.0 (SAS Institute, Cary, North Carolina).

\section{RESULTS}

\section{Baseline Patient Characteristics and Clinical Presentation}

Six patients included in this series had neural tube defects associated with spinal vascular malformations. In all cases, the malformations were classified as epidural fistulas (Table). Two patients were men and 4 were women. The mean age at presentation was 56.6 years. The coexistence of tethered cord and intradural lipoma was found in 4 cases (cases 1,2, 4, and 5). One patient had a disorder of cord formation with partial diastematomyelia with a tethered cord, while 2 had myelomeningoceles.

Clinical presentations included the following: 1) sensory changes in 6 patients, 2) bladder/bowel dysfunction in 4 patients, and 3) progressive motor weakness in 5 . All patients experienced some degree of neuropathic pain, sometimes bilateral with an ascending distribution. Symptom duration ranged from 1 to 12 months.

\section{Delayed Diagnosis and Prior Treatment}

In 3 cases, the vascular malformations were missed at first imaging, with a consequent delay in recognition ranging from 2 months to 2 years. The average time from symptom manifestation to diagnosis was 8 months. Two patients in this series had undergone myelomeningocele repair during childhood and presented decades later with an epidural AVF. Two additional patients underwent laminectomies before diagnosis of the fistula, which were remote from the site of the fistula. In 1 of these 2 patients, there was clear imaging evidence of an underlying vascular malformation before the laminectomy.

\section{Imaging Findings}

Enlarged vascular structures and flow voids were detected on MR imaging on the surface of the lower spinal cord in all patients. Five patients had T2 signal changes in the conus. Cord enhancement was detected in 3 patients.

Epidural arteriovenous fistulas were located at the sacral level in all patients except for 1 case in which it was located at the L4 level. Fistulas were fed by 1 vessel in 4 patients and by 2 separate arterial feeders in 2 patients. In all patients, the arterial feeder was the lateral sacral artery arising off the internal iliac artery, 4 from the left and 2 from the right. In 2 patients, both lateral sacral arteries fed the fistula. In all cases, while the actual arteriovenous shunt was extradural, secondary intradural venous drainage was present. None of the patients had a history of spinal hemorrhage.

\section{Treatment and Outcomes}

Five patients underwent transarterial embolization of the epidural fistula with Onyx (Covidien, Irvine, California). Postoperative MRA or DSA was performed in all cases within 24 hours to confirm closure of the fistula. One patient had a spinal cord infarct and consequent severe paraparesis due to embolization of an arterial feeder, which also supplied the anterior spinal artery. In 1 patient, symptoms were mild and not ascribable to the arteriovenous shunt; therefore, no invasive treatment was recommended.

Clinical and imaging follow-up ranged from to 2 to 14 months. Four patients clinically improved with regression of sensory symptoms after treatment. However, recovery of bladder and/or bowel function was slower compared with other motor and/or sensory neurologic symptoms. One patient did not recover urinary function completely. Following treatment, both the modified Rankin Scale and Aminoff Motor Disability Scale scores improved in 3 patients, were stable in 1 , and worsened in the patient who had a complication. Follow-up MR imaging showed 

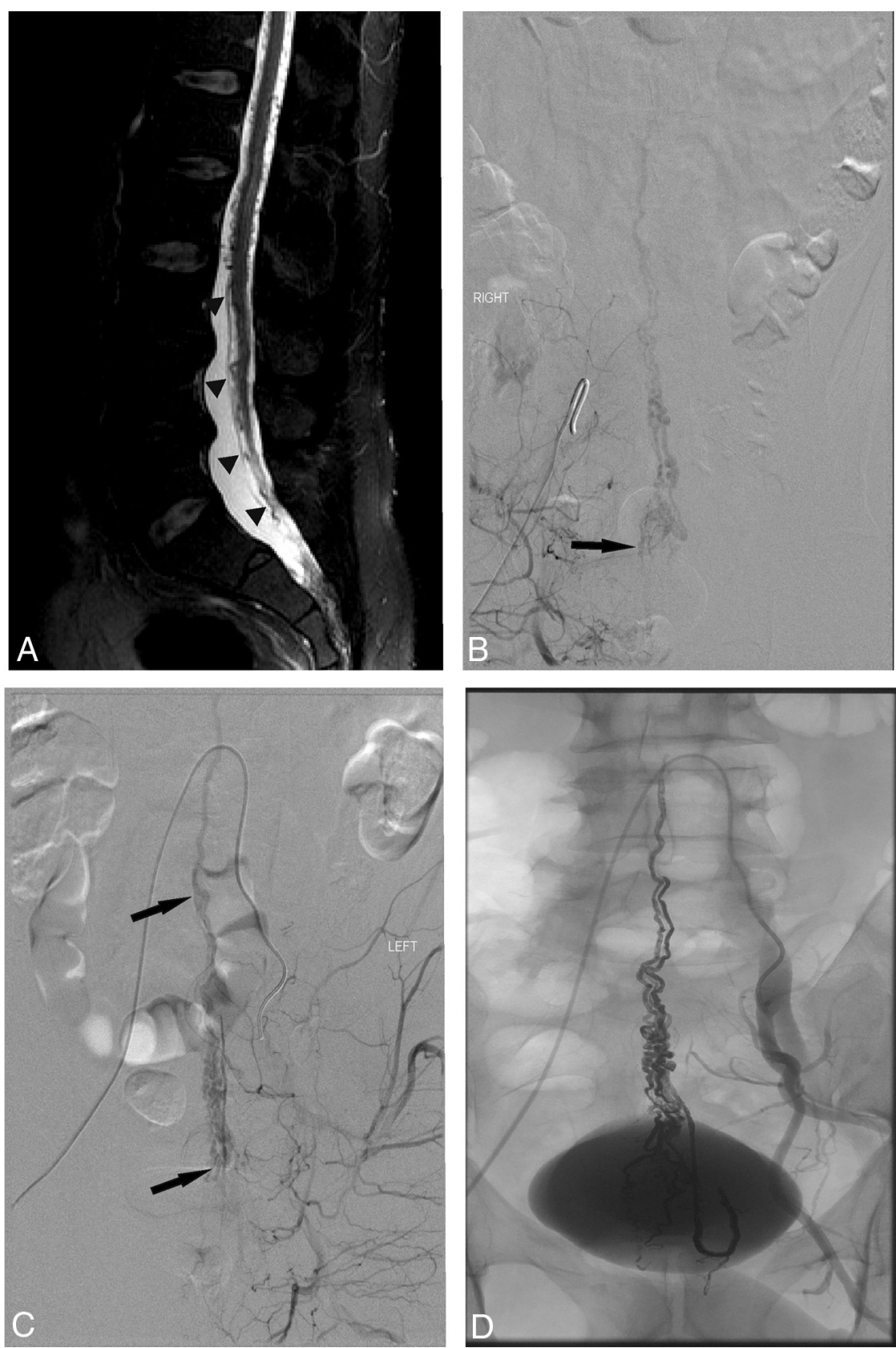

FIG 1. A, Sagittal T2-weighted spine MR imaging showing tethering of the spinal cord llower arrowheads). Note the conus tip at the L4-L5 level and flow voids throughout the spinal canal, most prominent in the sacral canal (arrowheads), extending superiorly to approximately the T2 level. $B$, Right internal iliac artery angiogram demonstrates an arteriovenous shunt in the spinal canal of the sacrum (black arrow). The feeding artery enters through the left S4 neural foramen. $C$, Left internal iliac artery angiogram demonstrates an additional feeder to the arteriovenous shunt (lower black arrow). Intradural draining veins (upper black arrow) are visible. D, Angiogram obtained following embolization demonstrates a large cast of Onyx extending from the site of fistula to the coronal venous plexus.

resolution of T2 hyperintensity in 5 cases. Spinal cord enhancement decreased in 2 .

\section{Case Examples}

Case 1. This 46-year-old man presented with a 2-decade history of back pain and bladder dysfunction following a motor vehicle collision (Fig 1). He had no history of an operation. Spine MR imaging showed tethering of the spinal cord, with the tip of the conus at the L4-L5 level. An intradural lipoma was identified posteriorly in the sacral canal, extending from S3 to S4, with cutaneous components from L3 to S4. There was mild displacement of the left S3 and S4 nerve roots. Enhancing vascularity throughout the spinal canal extended superiorly to the T2 level with numerous pial vessels along the posterior surface of the spinal cord.

Due to MR imaging findings consistent with a spinal vascular malformation, conventional spinal angiography was performed, which demonstrated an epidural arteriovenous fistula fed by a lateral sacral artery branch, which coursed through the left S4 neural foramen with a large draining vein coursing superiorly up into the thoracic region as well as some supply from the right lateral sacral artery.

The patient underwent embolization of the vascular malformation with Onyx 18. Postoperative angiography demonstrated complete obliteration of the fistula. Spinal MRA/MR imaging performed 2 months later did not show any evidence of residual fistula, and all T2 cord changes resolved. The patient reported decreased back pain following embolization, denying any new weakness, numbness, or bowel and bladder changes.

Case 2. This 44-year-old woman had a history of spina bifida surgery (L2-S1 laminectomy) when she was 10 years of age (Fig 2). The patient presented with a 3-year history of burning pain with progressive numbness ascending from her feet to thighs. The pain worsened with walking or lying in bed. Neurologic examination documented decreased temperature, pinprick, and touch sensation. The patient underwent spinal MR imaging, which demonstrated an unusual C1-C2 anomaly with absence of the odontoid process. Tortuous surface vascularity extended from the conus and along the entire dorsal thoracic cord with mild atrophy in the left upper cord (T3-T4). Signs of previous L2 laminectomy for spina bifida correction were recognized along with a prominent fatty placode in the posterior cord at the L4-5 level, which was tethered to the conus. MRA showed prominent tortuous dilated veins from the sacrum to the foramen magnum.

The patient underwent DSA with injection of the right internal iliac artery, which demonstrated an epidural spinal arteriovenous fistula fed by a branch of the lateral sacral artery. The fistula was 

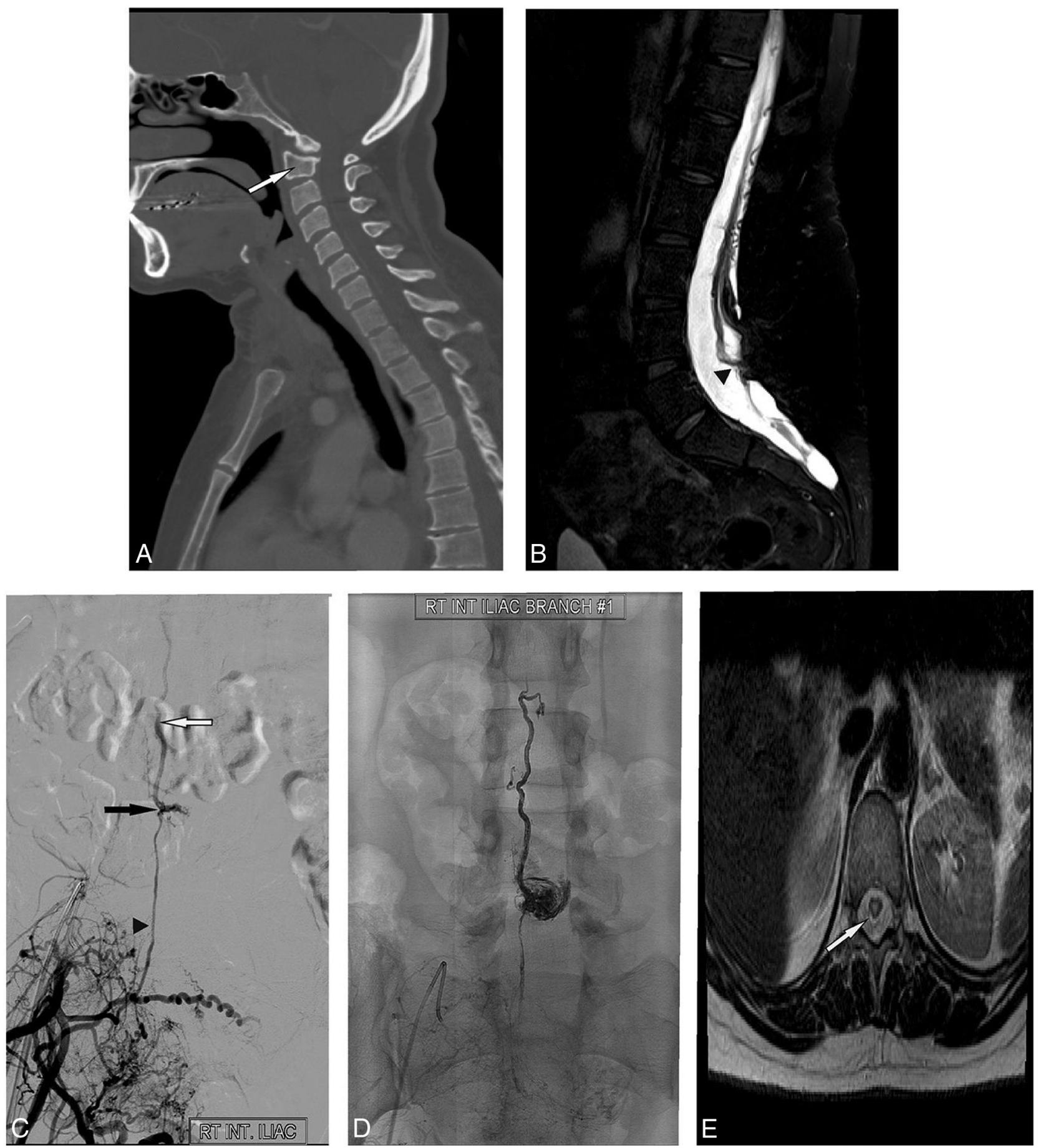

FIG 2. A, Sagittal noncontrast CT demonstrates the absence of the odontoid process (white arrow). B, Sagittal T2-weighted MR imaging of the lumbar spine shows tortuous dilated veins throughout the spinal canal. There is also a fatty placode in the posterior thecal sac at L4-5 (arrowhead), with conus tethering extending to the placode. C, Selective angiogram of the right lateral sacral artery (arrowhead) arising from the right internal iliac artery demonstrates an epidural spinal fistula (lower black arrow) with intradural venous drainage (upper white arrow) along the coronal venous plexus. $D$, Post-Onyx embolization $x$-ray image demonstrates an Onyx cast including the feeding artery, arteriovenous connection, and intradural draining vein. E, Axial T2-weighted MR imaging demonstrates myelomalacia of the central conus (arrow), consistent with cord infarction.

located at $\mathrm{L} 4-5$ in the region of the fatty placode. A large epidural vein ascended from this level and then coursed intradurally. The patient then underwent embolization with $3 \mathrm{~mL}$ of Onyx 18. Postoperative MRA showed a decreased tortuous dilated vein within the spinal canal.

The patient had a spinal cord infarction that led to postoperative lower extremity bilateral paresis. In retrospect, the arterial feeder to the fistula also supplied a small anterior spinal artery. The patient was admitted for a short rehabilitation in which she experienced progressive improvement of her weakness. Spinal MRA 3 months later showed that embolization resulted in significantly decreased vascularity within the spinal canal with nearly imperceptible flow voids. After 12 months, the patient continues to have significant diffuse pain and impaired mobility due to lower extremity weakness. 

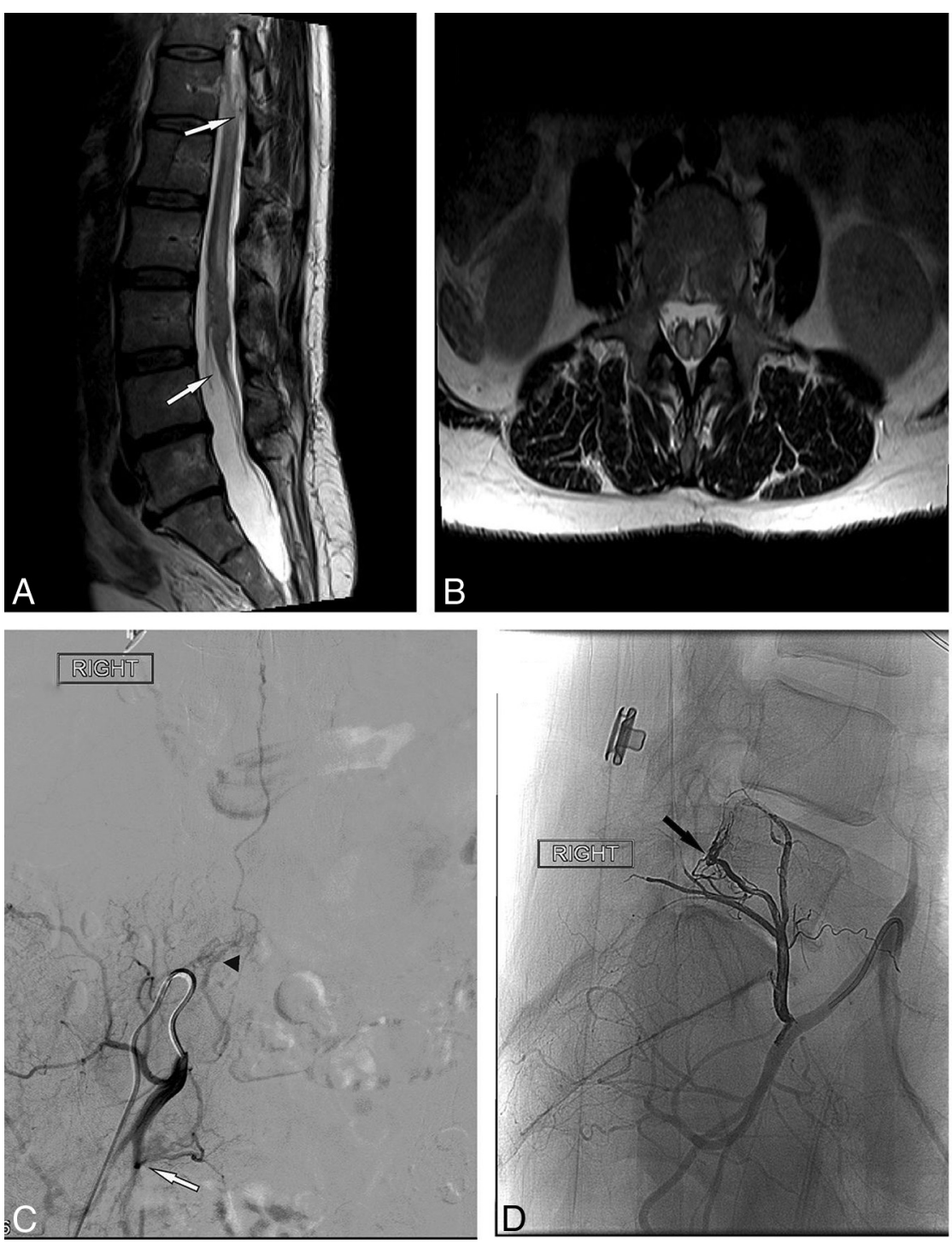

FIG 3. A, Sagittal T2-weighted MR imaging demonstrates tethering of the spinal cord with the tip of the conus at the L3-4 interspace (white arrow) before surgical release. There is high T2 signal of the cord and a faintly visualized flow void (upper white arrow). B, Axial T2-weighted MR imaging shows partial diastematomyelia in the lumbar spine without evidence of a fibrous band or boney spur/bar. High cord signal is present in both hemicords. C, Right internal iliac artery spinal angiogram demonstrates an epidural fistula arising from the right lateral sacral artery (white arrow) with an intradural draining vein (arrowhead). D, Post-Onyx embolization angiogram demonstrates an Onyx cast in the ventral epidural space of L5 (black arrow).

Case 3. This 65-year-old woman presented with stuttering/fluctuating lower extremity weakness with associated bladder hesitancy and bowel constipation (Fig 3). Spinal MR imaging at presentation demonstrated a thickened and congested spinal cord with the conus lying at the L3-L4 level. MR imaging showed some cord tethering along with partial diastematomyelia at L2-L3. On the basis of these imaging findings, which were obtained without contrast, the patient underwent laminectomy for cord untethering. Postoperatively, the patient declined to the point that she was no longer able to ambulate. A further MR imaging of the cervical and thoracic spine showed progression of the T2 signal abnormality and swelling within the central thoracic cord. On the basis of these findings, she was given a diagnosis of transverse myelitis and started on corticosteroids.

She then came to our institution for a second opinion. Spinal angiography confirmed an epidural fistula arising from the right lateral sacral artery. The feeding artery entered through the right L5 neural foramen with the epidural draining vein coursing down to the S1 nerve root sleeve. The patient underwent transarterial embolization of the feeding artery with Onyx 18. Follow-up angiography of the right internal iliac artery, left common iliac artery, middle sacral artery, and bilateral L3 lumbar arteries demonstrated no residual fistula. The patient's motor and sensory symptoms improved at 9 months, while impaired bladder control persisted. Spinal MRA and MR imaging performed at 10 months showed no residual fistula and significant improvement in long-segment cord edema.

\section{DISCUSSION}

Our case series of 6 patients with neural tube defects and associated spinal vascular malformations demonstrated several interesting findings. In all cases, the fistula associated with the neural tube defect was extradural and had secondary intradural venous drainage. The main arterial feeder was the lateral sacral artery in all 6 cases, and all fistulas were in the sacral or lower lumbar region. In 2 cases, it is conceivable that the fistula was a delayed complication of myelomeningocele repair performed at a young age; however, in the other 4 cases, the fistula was not associated with prior surgery. Because these fistulas were extradural and anatomically associated with the neural tube defect, our findings suggest that the association between the 2 pathologic conditions may share a causal relationship rather than representing a mere coincidence. The findings from our study are clinically relevant because they highlight the importance of carefully studying the spinal vascularity in patients with neural tube defects who develop myelopathic symptoms during adulthood.

Spinal vascular malformations associated with neural tube defects are uncommon, but several single case reports have been reported suggesting a possible causal relationship. In our review of the literature, we found 17 adults and 3 pediatric patients with a combination of spinal vascular malformation and neural tube defects (On-line Table). ${ }^{1-21}$ In accordance with our experience, these lesions were discovered, in most cases, during midadulthood with symptoms often attributable to both the arteriovenous fistula and tethered cord. Misdiagnosis and delay in symptom recognition were common, as demonstrated in our case series. Clinical presentations included sensory changes in $76 \%$ of pa- 
tients, bladder/bowel dysfunction in $67 \%$ of patients, and motor weakness in $80 \%$. Symptom duration was variable, ranging from 1 to 72 months. Arteriovenous fistulas were located at the sacral level in $29 \%$ of cases and at the lower lumbar levels in 57\%. Thirtyeight percent of vascular malformations were classified as spinal dural fistulas, whereas $62 \%$ were intradural arteriovenous fistulas or malformations. Only 1 case of extradural vascular malformation was documented, though the lower incidence of epidural shunts in the earlier reports may be related to less familiarity with this condition, which is diagnosed with much more frequency today due to advances in imaging and better understanding of the pathologic shunts. ${ }^{22}$ In $60 \%$ of patients, the feeder was the lateral sacral artery arising off the internal iliac artery, while the anterior spinal artery fed the malformation in $20 \%$. In most cases, intradural venous drainage was documented. None of the patients presented with hemorrhage. Surgical treatment was the preferred technique in $43 \%$ of reported cases, with embolization in $29 \%$. In the remaining third, a combined approach was chosen.

Some authors argue that the coexistence of neural tube defect and vascular malformation is the result of incomplete regression of mesenchymal tissue during the embryonic period. A premature disjunction of the neural ectoderm from the cutaneous ectoderm allows migration of the periaxial mesoderm into the developing neural tube. This mesenchyme migration could prevent adequate closure of the neural tube. ${ }^{5}$ While the pluripotent mesoderm primarily develops into fat, it may also develop into other tissues, including striated muscle, cartilage, fibrous bands, and blood vessels. Some authors argue that a failure to form the capillary component of the mesoderm might lead to the formation of a direct arteriovenous shunt. ${ }^{11}$ Other authors believe that mesenchymal cells forming the primordial vascular plexus are involved in the pathogenesis of arteriovenous fistulas with lipomyelomeningocele or lipoma. Vascular differentiation in fat tissue is suppressed by neural crest cells under normal conditions of development. However, if the neural crest cells are defective, inhibition fails and a lipoma may arise forming an AVM secondarily. ${ }^{10}$ It is speculated that the lipoma itself and its tethering effect further impair the venous drainage, resulting in venous hypertension and development of fistula-related symptoms.

While in 4 of our patients the epidural fistula was not associated with a prior surgery, in 2 patients, the fistula was diagnosed decades after surgical myelomeningocele repair. It is also conceivable that in these cases, the epidural fistula formed because of microvascular trauma during the reparative surgery, and the slow progressive hemodynamic changes associated with the low-pressure direct arteriovenous shunt may have only manifested clinically several years later. Such an association between surgery and extradural fistulas has been described. ${ }^{6,22}$ Some authors believe that AVF formation following spinal surgery is improbable and that a congenital association is more likely. ${ }^{14}$ However, any hypotheses regarding the pathogenesis of post-neural tube defect repair AVFs are purely speculative, especially given the paucity of cases in the literature. In cases in which the symptomatology worsens after surgical correction of a neural tube defect, careful study of the spinal vascularity is important. ${ }^{3}$ For example, in 1 case in our series, a patient presented with a myelopathy and MR imaging evidence of a spinal vascular malformation associated with a tethered cord and had exacerbation of the myelopathy following the untethering procedure. It was at that point that the fistula was discovered.

An epidural arteriovenous fistula associated with a neural tube defect can have important treatment implications as well. As demonstrated in our series, all patients with such malformations had lateral sacral artery feeders. Thus, when inspecting MR imaging before angiography, identification of a lumbar or sacral neural tube defect should prompt the angiographer to inspect these arteries first, possibly saving time during the spinal angiographic procedure. In 2 cases, we found that an anterior spinal artery arose from the lateral sacral artery. This is a relatively rare occurrence. Prior cadaveric studies suggest that the presence of an anterior spinal artery arising at the sacral level is $<3 \%{ }^{23}$ This is important because failure to identify an anterior spinal artery arising from such a low level can have disastrous consequences as demonstrated in case 2 .

\section{Limitations}

Our study has limitations. This was a small case series on a rare entity; thus, no statistical comparisons were made. Preoperative imaging was not available for the 2 patients who were treated in childhood for their myelomeningoceles; thus, we are unable to determine whether the fistulas in these cases were present before the operation. This study was a retrospective chart review, so it is prone to various forms of bias, including selection bias. Last, there is a wide range in the amount of posttreatment follow-up the patients received.

\section{CONCLUSIONS}

In this report, we present the first series of epidural arteriovenous fistulas associated with neural tube defects. The rare concurrence of neural tube defects with spinal vascular malformations is something that should be considered when evaluating a patient with a neural tube defect and myelopathy. The pathophysiology of these entities is still a matter of debate, with most authors speculating that these lesions form due to a defect in migration of embryologic layers during neural tube formation. However, due to the paucity of cases reported in literature and the small size of this case series, all hypotheses are purely speculative. Nevertheless, the increasingly reported association between 2 uncommon pathologic conditions raises the strong possibility of a causal relationship between the two. When one evaluates these patients, attention should be paid to identifying the anterior spinal artery arising from a low-lying artery such as the lateral sacral artery.

Disclosures: Giuseppe Lanzino-UNRELATED: Consultancy: Medtronic/Covidien* Waleed Brinjikji-UNRELATED: Consultancy: Cerenovus; Employment: Marblehead Medical LLC, Comments: chief executive officer. *Money paid to the institution.

\section{REFERENCES}

1. Chanthanaphak E, Pongpech S, Jiarakongmun P, et al. Filum terminale arteriovenous fistulas: the role of endovascular treatment. J Neurosurg Spine 2013;19:49-56 CrossRef Medline

2. Chatkupt S, Ruzicka PO, Lastra CR. Myelomeningocele, spinal arteriovenous malformations and epidermal nevi syndrome: a possible rare association? Dev Med Child Neurol 1993;35:737-41 Medline

3. Cheung AC, Kalkanis SN, Ogilvy CS. Paraplegia after tethered cord surgery: an uncommon combined anomaly of spinal arteriovenous 
fistula and sacral lipoma: case report. Neurosurgery 2005;57:E598; discussion E598 CrossRef Medline

4. Djindjian $\mathrm{M}$, Ayache $\mathrm{P}$, Brugieres $\mathrm{P}$, et al. Sacral lipoma of the filum terminale with dural arteriovenous fistula: case report. J Neurosurg 1989;71:768-71 CrossRef Medline

5. Erdogan C, Hakyemez B, Arat A, et al. Spinal dural arteriovenous fistula in a case with lipomyelodysplasia. Br J Radiol 2007;80:e98100 Medline

6. Gross BA, Du R. Spinal pial (type IV) arteriovenous fistulae: a systematic pooled analysis of demographics, hemorrhage risk, and treatment results. Neurosurgery 2013;73:141-51; discussion 151 CrossRef Medline

7. Hurst RW, Bagley LJ, Marcotte P, et al. Spinal cord arteriovenous fistulas involving the conus medullaris: presentation, management, and embryologic considerations. Surg Neurol 1999;52:95-99 CrossRef Medline

8. Kendall BE, Logue V. Spinal epidural angiomatous malformations draining into intrathecal veins. Neuroradiology 1977;13:181-89 CrossRef Medline

9. König M, Hentsch A, Schmieder K, et al. Extraspinal dural arteriovenous fistula in a patient with lipomyelodysplasia: value of MRI and MRA. Neuroradiology 1999;41:579-83 CrossRef Medline

10. Krisht KM, Karsy M, Ray WZ, et al. Extraspinal type I dural arteriovenous fistula with a lumbosacral lipomyelomeningocele: a case report and review of the literature. Case Rep Neurol 2015;2015:526321 CrossRef

11. Lee JH, Chung CK, Choe G, et al. Combined anomaly of intramedullary arteriovenous malformation and lipomyelomeningocele. AJNR Am J Neuroradiol 2000;21:595-600 Medline

12. Lim SM, Choi IS, David CA. Spinal arteriovenous fistulas of the filum terminale. AJNR Am J Neuroradiol 2011;32:1846-50 CrossRef Medline

13. Macht $\mathrm{S}$, Chapot $\mathrm{R}$, Bieniek $\mathrm{F}$, et al. Unique sacral location of an arteriovenous fistula of the filum terminale associated with di- astematomyelia and lowered spinal cords. Neuroradiology 2012;54: 517-19 CrossRef Medline

14. Mavani SB, Nadkarni TD. Tethered cord due to caudal lipomeningocele associated with a lumbar dural arteriovenous fistula. J Neurosurg Spine 2014;21:489-93 CrossRef Medline

15. Rajeev K, Panikar D. Dural arteriovenous fistula coexisting with a lumbar lipomeningocele: case report. J Neurosurg Spine 2005;3: 386-89 CrossRef Medline

16. Rice JF, Jelsma RK. Combined arteriovenous malformation and intramedullary lipoma: surgery and embolotherapy. AJNR Am J Neuroradiol 1986;7:171-73 Medline

17. Sato M, Takigawa T, Shiigai M, et al. Spinal dural arteriovenous fistula with lipomyelodysplasia. Neurol Med Chir (Tokyo) 2013;53: 107-09 Medline

18. Srinivasan A, Roy NK, Ghuman MS, et al. Spinal dysraphism masking the presentation of spinal dural arteriovenous fistula: a serendipitous development or a congenital predisposition to an earlyonset variant of spinal dural arteriovenous fistula? Neurol India 2016;64:1380-81 CrossRef Medline

19. Tubbs RS, Oakes WJ. Lipomyelomeningocele and arteriovenous malformation: case reports and a review of the literature. Childs Nerv Syst 2006;22:628-31 CrossRef Medline

20. Weon YC, Chung JI, Roh HG, et al. Combined spinal intramedullary arteriovenous malformation and lipomyelomeningocele. Neuroradiology 2005;47:774-79 CrossRef Medline

21. Wortsman J, Chui M, Gray T, et al. Spinal meningeal AVM supplied from the internal iliac artery associated with tethered cord syndrome in an adult: case report. J Can Assoc Radiol 1983;34:323-25 Medline

22. Nasr DM, Brinjikji W, Clarke MJ, et al. Clinical presentation and treatment outcomes of spinal epidural arteriovenous fistulas. J Neurosurg Spine 2017;26:613-20 CrossRef Medline

23. Kroszczynski AC, Kohan K, Kurowski M, et al. Intraforaminal location of thoracolumbar anterior medullary arteries. Pain Med 2013; 14:808-12 CrossRef Medline 